\title{
THOMAS DAVATZ REVISITADO: REFLEXÕES SOBRE A IMIGRAÇÃO GERMÂNICA NO SÉCULO XIX*
}

\author{
Ilka Stern Cohen \\ Doutoranda Depto. de História-FFLCH/USP
}

\section{Resumo}

Lido isoladamente, o relato de Thomas Davatz pode ser tido como mais um dos tantos "olhares estrangeiros" aqui publicados. Colocado no quadro das publicações em língua alemã voltadas para a questão da emigração, as memórias de Thomas Davatz revelam uma vertente menos explorada pela historiografia brasileira. Este artigo consiste numa primeira incursão nesse campo de pesquisa.

\section{Abstract}

Thomas Davatz's book is a testimony about his experience in Brazil and a reflection about European emigration. If it's possible to read the book as a simple personal testimony, on the other hand it's possible to think about it conjoined to some other papers, books and memories wrote by German emigrants, publishers and people interested on the emigration business. This is a first essay in this research branch.

\section{Pallavras-Chave}

Emigração Alemã -Memória-Colônia de Parceria-Tráfico Mão-de-obra

\section{Keywords}

German Emigration - Memories - Parceria - Workers traffic

\footnotetext{
* Estas reflexões foram desenvolvidas a partir de um trabalho realizado em conjunto com Ana Luiza Martins, que resultou no livro O Brasil pelo olhar de Thomas Davatz, (1856-1858), São Paulo, Atual, 2000.
} 
S escritos dos viajantes estrangeiros que visitaram o Brasil no século XIX tornaram-se, nas últimas décadas, um dos temas prediletos dos estudiosos das ciências sociais em geral, além de transportar o "olhar estrangeiro" para além dos domínios da universidade ${ }^{1}$.

Essa questão, no entanto, não é nova. As memórias de estrangeiros constituem um tema na medida em que têm estreita relação com a preocupação com a questão da identidade nacional, tema de importância marcante e recorrente entre os intelectuais brasileiros ${ }^{2}$. A visão que se tem do país, o tom de observação dos costumes, a crônica do quotidiano presente em muitos desses escritos compõem uma imagem que de alguma maneira se reflete nas reflexões sobre a identidade nacional; conforme observa Ana Maria Beluzzo, "Na iconografia e na crônica de autores viajantes nem sempre chegamos a protagonistas. Somos vistos, sem nos termos feito visíveis. Fomos pensados. Ainda assim, essas visões alimentam lembranças do passado e povoam nosso inconsciente" (Beluzzo, 1990: 15).

Além das descrições e relatos de viajantes, o século XIX foi pródigo na produção de imagens, registradas pelos artistas que acompanhavam as expedições de visitantes e exploradores. Em ambos os casos, o que sempre ressalta é uma visão entusiasmada da exuberância da natureza, acentuando o exotismo como uma de nossas mais fortes características. Contudo, como acentua Renata Dória, “o perigo é nos deixarmos reduzir a apenas uma dimensão (...). Nesse sentido, a sedução do pitoresco pode ajustar-se a um projeto que evita as desigualdades do visível, incorporando a variedade aos personagens e situações sem de fato enfrentá-los em sua complexidade"(Dória 1999:132).

\footnotetext{
${ }^{1}$ A divulgação dessa literatura atinge atualmente a escola de primeiro grau, como o demonstram as coleções para-didáticas "O olhar estrangeiro" da Atual Editora, e "Viajantes estrangeiros", da Editora Ática. Em âmbito mais amplo, destaca-se a exposição denominada "O Brasil dos viajantes”, realizada em 1996 no Museu de Arte de São Paulo, na qual se expunham alguns artefatos e ampla produção iconográfica que refletia o imaginário europeu acerca do Novo Mundo, e do Brasil em especial.

${ }^{2}$ Cf. por exemplo Sussekind, Flora (1990), onde se analisa a marca impressa pelo olhar estrangeiro na constituição de nossa vida literária.
} 
De fato, o "olhar europeu" sempre teve um peso específico na construção dos diversos discursos sobre a questão da identidade nacional. Nos anos 1930, esse debate se intensifica e se desdobra, manifestando-se inclusive no incremento da vida editorial: surgem a Coleção Azul, editada por Afonso Schmidt, a Brasiliana, publicada pela Companhia Editora Nacional, e a Biblioteca Histórica Brasileira, pela Martins (Hallewell 1985). A primeira refletia o calor do debate político, discutindo temas como o tenentismo, a organização nacional, os rumos para o futuro ${ }^{3}$. A segunda, iniciada em 1931, nasceu com a intenção de resgatar as grandes figuras do passado e "pode ser encarada como uma das primeiras manifestações do novo interesse pelo Brasil e por sua herança " (Hallewell 1985: 301).

É na esteira dessas preocupações que se pode compreender a organização, no final dos anos 1930, da Biblioteca Histórica Brasileira, publicada pela Livraria Martins Editora. Os objetivos dessa coleção estão explicitados na introdução de Sérgio Milliet ao quarto volume da coleção, o de Jean-Baptiste Debret: "A escrita de um Rugendas ou de um Debret assemelha-se antes à de um chefe de seção, em seus pobres relatórios, que à de um literato habituado ao valor das palavras e aos segredos da sintaxe [...] Bem sei que se pode perguntar: por que então traduzir essas obras? Evidentemente do ponto de vista literário não haveria motivo algum para fazê-lo. Mas nem só de literatura vive o homem; ao contrário, cada vez menos vive dela. E cada vez mais de documentos, de dados objetivos, úteis à solução de seus problemas hodiernos" (Milliet s/d).

Percebe-se assim a preocupação em resgatar os registros produzidos pelos viajantes europeus levando em consideração especificamente seu caráter documental. O coordenador da coleção foi Rubens Borba de Moraes, bibliófilo que então frequientava os círculos intelectuais paulistas e dirigia a Biblioteca Municipal de São Paulo. Preocupado com a qualidade e a importância das obras publicadas, ele convidou, para traduzir e

\footnotetext{
${ }^{3}$ Vavy Pacheco Borges (1992) analisa a dimensão política contida na polêmica entre Virgínio de Santa Rosa e Alcindo Sodré, respectivamente em A desordem, A gênese da desordem e $O$ sentido do tenentismo, publicados em 1932 e 1933 na coleção Azul.
} 
escrever a introdução aos volumes, intelectuais de grande destaque, como Sérgio Milliet, Afonso Arinos de Mello Franco e Sérgio Buarque de Holanda entre outros.

Considerando que essas obras não eram exclusivamente escritas, mas também registros iconográficos de grande valor, uma das maiores preocupações de Rubens Borba de Moraes consistia em garantir a impressão da melhor qualidade gráfica. $\mathrm{O}$ projeto era bastante ambicioso, pois além da edição normal, previa-se a tiragem de uma edição de luxo. É o que fica patente em sua correspondência com Sérgio Buarque de Holanda, quando expõe as dificuldades no cumprimento dos prazos e no ritmo da produção da coleção; em carta sobre as questões que o afligiam, Rubens Borba de Moraes explicava tal demora em parte devido a questões financeiras, pois "o Debret exigiu 'capitais consideráveis' do amigo Martins" ".

O quinto volume da coleção foi o das Memórias de um colono no Brasil, de Thomas Davatz; ao incluir o título, Rubens Borba de Moraes deixou clara a importância do texto, que considerava uma preciosa fonte para o estudo da colonização em São Paulo. Para traduzir obra tão significativa, Rubens Borba de Moraes convidou Sérgio Buarque de Holanda, eminente historiador. Ao fazer o convite, o coordenador assinalava sua paixão pelo tema da colonização paulista e sugeria ao historiador que o desenvolvesse: "Se você acha que seria útil fazer-me um 'prefácio-estudo' sobre a questão eu te peço que faça. O que você acha? Seria talvez melhor. Eu sou tão apaixonado por esta questão do estudo da colonização, tenho estudado tanto esse problema que gostaria até de escrever um livro sobre o assunto. Mas eu tenho preguiça de escrever livros. Prefiro 'fazer livros'. É mais divertido. Mas você por que não escreve esse livro? Vamos, avante! Faça um prefácio para o Davatz com as diretrizes do futuro livro",

\footnotetext{
${ }^{4}$ Carta de Rubens Borba de Moraes a Sérgio Buarque de Holanda, 30 de agosto de 1940. A correspondência de Sérgio Buarque de Holanda está depositada no Arquivo Central do IFCH da Universidade de Campinas.

${ }^{5}$ Carta de Rubens Borba de Moraes a Sérgio Buarque de Holanda, 18 de maio de 1940.
} 
De fato, o prefácio de Sérgio Buarque de Holanda se tornou um marco na historiografia sobre a colonização paulista. Nesse estudo desenvolveu-se pela primeira vez uma análise aprofundada da experiência da parceria, baseada no relato do colono Thomas Davatz. Assim, foi como um documento "sobre a colonização de São Paulo" que esse depoimento se consagrou. Ao texto original, Sergio Buarque de Holanda acrescentou um conjunto de fontes sobre o levante dos colonos, além de extensa bibliografia que se tornou o esteio sobre o qual se montaram os mais diversos trabalhos sobre emigração e trabalho livre em São Paulo no século XIX. A questão da parceria tornou-se um tema ${ }^{5}$. O brilho do prefaciador ofuscou-evidentemente sem intenção - o prefaciado.

Em sua apresentação do texto, Rubens Borba de Moraes não deixa de assinalar que o livro "não é imparcial; é o libelo acusatório de um colono contra o patrão". Mais que isso, é o único depoimento existente "escrito pela parte mais interessada: o colono" (Davatz 1980: 13). Contudo, enfatizando a questão da colonização, apagam-se alguns outros aspectos da obra. Nesse sentido, parece significativo que "O tratamento dos colonos na Província de São Paulo no Brasil e o levante contra seus opressores. Um apelo e alerta aos amigos e autoridades dos estados aos quais os

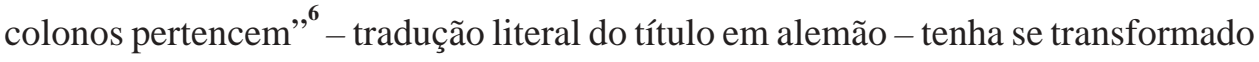
em Memórias de um colono no Brasil. O título originalmente contundente suavizouse em português, encobrindo de pronto o conteúdo explosivo do livro. Evidentemente não se trata aqui de questionar o tradutor, ou de discutir uma opção que pode ter sido editorial; trata-se apenas de registrar a diferença.

A obra já era conhecida em São Paulo pelo círculo de intelectuais ligados a João Francisco (Yan) de Almeida Prado, que possuía o original. Mário de Andrade leu o

\footnotetext{
${ }^{5}$ Os estudos pioneiros sobre a parceria são os de Emília Viotti da Costa (1977) e José Sebastião Witter (1974).

${ }^{6}$ Die behandlung der Kolonisten in der Provinz São Paulo in Brasilien und deren Erhebung gegen ihre Bedrücker. Ein Noth-und Hilfruf an die Behörden und Menschenfreunde der Länder und Staaten, welchen die Kolonisten angerhörten, Chur, 1858.
} 
texto e escreveu dois artigos, publicados consecutivamente no Diário Nacional. Nesses fica evidenciada uma abordagem política da obra, dando oportunidade ao cronista de tecer comentários irônicos sobre as mazelas da política paulista no momento.

O primeiro artigo, datado de 9 de agosto de 1931, expunha o conteúdo geral da obra e considerava o livro "uma das informações mais interessantes sobre a colonização teuto-suíça tentada pelo senador Vergueiro". Comparando-o a tantos outros escritos de viajantes, Mário de Andrade acentuava "o tom mais ou menos monótono e sabido nas duas primeiras seções, que tratam das condições gerais da província e das tentativas de colonização.” Davatz era considerado desinteressado e pouco observador, mas em contrapartida o cronista elogiava o tom do relato, "a ingenuidade dele e o ar sincero da escrita, que por esses dois caracteres possivelmente se aproxima da verdade",

Prosseguindo em tom irônico e velado sua crítica ao momento presente, Mário de Andrade se deliciava com o tom surpreso de Davatz diante dos desmandos e engodos sofridos pelos colonos e imigrantes: "De resto, também no sul os alemães do tempo da Independência tinham sido ludibriados, pelo que referem os alemães da época como Schumacher ou Schlithorst. Os livres suíços que vinham para Ibicaba volupiados pelas lendas duma terra de oiro, garantidos por contratos aperitivantes de arrendamento à meia e trato melhor que os das aldeias nevadas, encontravam era uma legítima escravidão",

Em breve resumo do texto, Mário de Andrade descrevia as condições de vida dos colonos, a burla dos contratos, os engodos e principalmente os mecanismos de opressão que transformavam os trabalhadores formalmente livres em escravos brancos: "o processo de escravização do colono era endividá-lo inicialmente para que ele depois não pudesse mais se libertar do fazendeiro" ${ }^{9}$. Ao reproduzir as acusações do autor, Mario de Andrade resgatava toda uma visão negativa do sistema de colonização instituído pelos fazendeiros paulistas no século anterior, contrariando a visão oficial da parcela da elite à qual se opunha politicamente.

\footnotetext{
7 “Agora é não desanimar!... I” Diário Nacional, 9 de agosto de 1931, p. 7.

${ }^{8}$ ibidem.

${ }^{9}$ ibidem.
} 
Esse comentário aparentemente provocou reações ${ }^{10}$, pois no segundo artigo, publicado na semana seguinte, o autor iniciava com uma explicação irônica: "O interesse apenas de cronista, pelas anedotas que tinha a relatar, me fizeram esquecer que sem ressalva alguma de minha parte o relato iria ferir o sentimento daqueles que guardam com justiça a memória do velho paulista [...] está claro que com meu artigo de domingo passado não tive a mínima intenção de chocar o sentimento de ninguém. Nem mesmo de diminuir as benemerências do senador Vergueiro[...] quis foi dar conta de um livro que poucos conhecem, cujo valor é inegável para nós e cujas anedotas divertiam. Mas que a verdade dele seja incontestável, não posso afirmar "11 .

E nesse segundo artigo, em que reproduz o relato sobre o levante dos colonos de Ibicaba, ele remete claramente à continuidade dos métodos da política, que permaneciam semelhantes: "Na descrição desse 'levante dos colonos contra seus opressores' o livro se torna interessantíssimo: os processos mais perrepistas de opressão, de disfarce, de prepotência são utilizados contra os colonos e especialmente contra Davatz. Este é um 'revolucionário' ameaçado de morte, com negrões assalariados esperando ele ( $\mathrm{sic}$ ) nas tocaias da noite; o protesto dos colonos é desvirtuado como um novo Palmares perigosíssimo"

Como se percebe, o livro de Thomas Davatz constituía não apenas mais uma mera descrição do Brasil pitoresco que se esperava de um estrangeiro, mas abordava temas delicados como a opressão, os desmandos dos poderosos, as reações dos oprimidos, temas certamente pouco confortáveis e principalmente pouco conhecidos pelo público leitor nacional. A importância do texto foi mais uma vez acentuada adiante, quando, num inquérito promovido pela revista Rumo em 1933, Mário de

\footnotetext{
${ }^{10}$ Uma análise literária desses dois artigos está em Telê Ancona Lopez, introdução a Mario de Andrade (1976:47-48).

11 “Agora é não desanimar! II Diário Nacional, 16 de agosto de 1927, p. 7.

12 “Agora é não desanimar! I, op. cit. Grifo meu. Cabe notar que o Diário Nacional, jornal publicado entre 1927 e 1932, era o órgão oficial do Partido Democrático, oposição ao Partido Republicano Paulista, detentor exclusivo do poder no estado até 1930.
} 
Andrade reafirma sua admiração pela obra, incluindo-a entre os 20 títulos que se deve ler para conhecer o Brasil ${ }^{13}$.

\section{II}

Assim, se por um lado é possível, e quase que obrigatório, utilizar as memórias de Thomas Davatz como fonte sobre a colonização em São Paulo, também é possível considerá-lo em outras dimensões. Afinal de contas, não se deve esquecer que o texto foi escrito para os europeus, e com o fim precípuo de evitar que se continuasse imaginando a vinda para o Brasil como a solução para os problemas encontrados na Suíça naquele momento. Convém portanto retomar a questão da emigração no contexto em que se dá a vinda desse grupo de suíços na segunda metade do século XIX.

A entrada de povos de língua alemã no Brasil ocorreu em momentos distintos. Não é propósito deste artigo abordar esta questão, de resto já bastante estudada. Cabe apenas lembrar que as primeiras iniciativas para atrair europeus datam da chegada da Corte portuguesa em 1808; emigrantes alemães e suíços ocuparam algumas faixas de terra no Espírito Santo e na região serrana do Rio de Janeiro, e imigrantes açorianos e alemães foram atraídos para a fronteira meridional e ainda para São Paulo ${ }^{14}$. A segunda grande onda imigratória verificou-se a partir de 1870 , quando o governo do estado de São Paulo assumiu oficialmente a promoção da emigração para resolver a questão premente do trabalho nas fazendas de café.

$\mathrm{O}$ momento a que nos referimos neste artigo encontra-se a meio caminho entre essas duas iniciativas. Trata-se da primeira experiência de importação de mão-deobra para a lavoura, promovida por uma companhia de colonização organizada pelo Senador Nicolau de Campos Vergueiro na segunda metade da década de 1840. Proprietário de grandes fazendas no oeste do estado, o senador associou-se a seus filhos para fundar uma empresa de colonização cujo objetivo consistia na importação de mão de obra para o trabalho nas fazendas de café sob o sistema da parceria.

\footnotetext{
${ }^{13}$ Rumo, ano I, no., 3, p. 7.

${ }^{14}$ Sobre o tema cf. Oberacker (1976); Nicoulin (1995); Seyferth (1990); Seyferth (2000).
} 
Aparentemente a opção pela colonização suíça esteve relacionada ao fato de o senador Vergueiro estar ligado a Carlos Perret-Gentil, vice-cônsul suíço; é de autoria deste um livro inteiramente elogioso sobre a colônia de parceria de Ibicaba e, segundo informações de um autor, Perret-Gentil estava associado a Vergueiro na companhia de colonização ${ }^{15}$.

Em princípio organizada para resolver os problemas das terras da família, a companhia de colonização acabou por se transformar num comércio muito semelhante ao do tráfico de escravos negros, uma vez que os futuros colonos eram repassados aos fazendeiros interessados mediante a assunção das responsabilidades para com esses, além de um pagamento à Vergueiro \& Cia. As primeiras levas de imigrantes contratados chegaram ao Brasil em 1845, e eram predominantemente portuguesas. Em 1848, com a companhia de colonização já organizada, vieram as primeiras famílias de língua alemã, provenientes dos vários estados germânicos ${ }^{16}$. O grupo ao qual pertencia Thomas Davatz chegou ao Brasil em julho de 1855.

Thomas Davatz - mestre-escola da pequena aldeia de Fanas, no cantão suíço dos Grisões, decidiu emigrar para o Brasil em 1854. Como membro da Comissão dos Pobres de sua comunidade, liderou a vinda de um dos grupos de emigrantes contratados pela Vergueiro \& Companhia. Depois de trabalhar por um ano e meio na fazenda Ibicaba, de propriedade do Senador, Davatz liderou um movimento de reivindicação por melhores condições de trabalho e pelo fim da exploração dos colonos, o que provo-

\footnotetext{
${ }^{15}$ A Vergueiro \& Comp. tinha ainda atividades comerciais em Santos. Detalhes sobre sua fundação estão em Djalma Forjaz, O senador Vergueiro - Sua vida e sua época (1778-1859). São Paulo, Oficinas do Diário Oficial (1924: 45). Também é deste autor a informação de que uma das filhas do senador, Ana, era casada com uma filha do vice-cônsul Perret-Gentil; sobre a participação deste na empreitada da colonização, cf. Weinziger, F. F. Colônia Helvetia no Brasil. São Paulo, Escolas Profissionais Salesianas (1935: 6). Quanto ao referido livro sobre Ibicaba, trata-se de A colônia Senador Vergueiro. Considerações de Carlos Perret-Gentil, vice-cônsul da Suissa no Rio de Janeiro. Santos, Typographia Imparcial, 1851.

${ }^{16}$ Cabe lembrar que nesse momento a Alemanha ainda não constituía um país unificado, mas um conjunto de estados independentes; por esse motivo, é mais conveniente falar em povos de língua alemã, em cuja esfera de influência se encontram os suíços.
} 
cou sua expulsão da fazenda e seu regresso à Suíça. Suas memórias constituem um depoimento sobre a experiência e ao mesmo tempo uma defesa de suas posições.

Davatz tinha ainda como missão oficial enviar à Suíça um relatório acerca das condições de vida e trabalho na colônia, que servisse de orientação às autoridades suíças quanto à política de emigração. Essa posição de destaque no grupo pode explicar o tratamento especial dispensado a ele e a sua família. As despesas de viagem foram adiantadas em 1/4 pela companhia Vergueiro; as acomodações no navio eram melhores que a dos companheiros, assim como a casa que recebeu na colônia; logo após sua chegada, o diretor da fazenda aconselhou-o a aprender português para que pudesse assumir um cargo na administração da colônia; meses mais tarde, começou a dar aulas e chegou a ministrar uma cerimônia religiosa no culto protestante. Em suma, pode-se dizer que do ponto de vista estritamente pessoal, não haveria muito de que se queixar ${ }^{17}$. Por que então Thomas Davatz escreve o livro? Segundo suas próprias palavras, para "contribuir com todas as minhas forças para que os pobres colonos ali perdidos [...] possam ser amparados devidamente [...]; um segundo objetivo [...] é o de advertir tanto quanto possível contra a leviandade das emigrações e trabalhar um pouco para que se acalme a febre de emigrar [...], poupando a muita gente amargas desilusões" (Davatz 1980:50). É este segundo aspecto que nos interessa explorar.

Desde o início do livro, evidencia-se a clara intenção do autor de combater o movimento emigratório que se desencadeava em sua pátria. Além de escrever em socorro de seus companheiros colonos que permaneceram no Brasil após sua expulsão, nosso autor pretendia "advertir tanto quanto possível contra a leviandade das emigrações e trabalhar um pouco para que se acalme a febre de emigrar, mesmo quando ela se dirige a outros centros [...] poupando a muita gente amargas desilusões" (Davatz 1980:50).

\footnotetext{
${ }^{17}$ Segundo Warren Dean, a companhia Vergueiro tinha conhecimento da missão assumida por Davatz junto aos deputados suíços; assim, o bom tratamento dispensado à família ocultava a esperança de obter "possivelmente, segundo presumia Davatz, [... ] um relato favorável (1977: 104). Este autor relata minuciosamente o caso de Ibicaba. Também o dr. Heusser aponta os privilégios concedidos a Davatz, como por exemplo as condições excepcionais em que recebera o adiantamento e o pagamento de juros sobre as despesas assumidas (Heusser: 15).
} 
Ao longo de todo o texto, o autor confessa seu arrependimento por ter vindo para o Brasil, referindo-se não apenas à sua iniciativa pessoal, mas ainda por se sentir responsável pela decisão de muitos elementos de seu grupo. Foi por iniciativa sua que a comuna de Fanas aceitou financiar a viagem de alguns de seus companheiros: "Em agosto de 1854 meus pensamentos [se voltaram] para o Brasil. Ali meus lindos desejos seriam uma realidade, segundo faziam crer numerosas descrições que vinham em palestras, em cartas, em impressos, em explicações de toda sorte. Nessa alegre esperança decidi, como membro da Comissão dos Pobres, dirigir uma proposta à minha municipalidade, sugerindo que esta proporcionasse os recursos necessários aos cidadãos que quisessem embarcar para o Brasil sem dispor dos meios com que pagar a viagem" (Davatz 1980: 161).

O livro compõe-se de três partes. A exemplo de inúmeros outros relatos de viajantes, a primeira delas descreve os aspectos naturais e materiais de São Paulo, detalhando as questões relativas a solo, clima recursos naturais, etc. Obedecendo ao roteiro de questões previamente formulado pelos deputados suíços, expõe com clareza as condições de vida e as dificuldades de adaptação ao novo ambiente, procurando “[...] ter em vista única e exclusivamente a verdade, e, alheio a quaisquer considerações de interesse particular, próprio ou estranho, referir apenas aquilo que possa atestar perante sua consciência e diante de Deus"(Davatz 1980: 260), conforme se comprometera.

As observações de Davatz estão marcadas por uma visão extremamente negativa das regiões pelas quais passou e, evidentemente, da colônia em que se estabeleceu. Destoando do entusiasmo que geralmente marca o olhar estrangeiro quanto à exuberância da natureza, o texto a caracteriza como assustadora e incômoda, exigindo esforços hercúleos para dominá-la. Desde as necessidades de cultivo até os mínimos detalhes, como a questão dos insetos, tudo é descrito de forma desalentadora, capaz de desencorajar os eventuais interessados numa aventura. Quem escreve não é um naturalista estudando a paisagem, mas uma vítima das ilusões construídas sobre falsa propaganda: "Perdoe-me o leitor benigno se o detive longamente antes de familiarizá-lo com o tratamento imposto aos colonos. Cumpre-me, além de tudo, lançar uma advertência contra a mania fútil e leviana de se fugir para as outras terras. Assim 
sendo, devo pintar, com meus parcos recursos, o país para onde se volvem tantos anseios e aspirações" (Davatz 1980:84).

A segunda parte do texto expõe detalhadamente o quotidiano do trabalho nas fazendas, acentuando o aspecto negativo oculto por um contrato ambíguo ou simplesmente não respeitado pelos fazendeiros. Nesse capítulo, Davatz descreve o trabalho na fazenda, as tarefas e obrigações dos colonos e, em especial, os mecanismos pelos quais o contrato de parceria transformava o colono num escravo, na medida em que seu endividamento era sempre maior do que o pagamento que lhe cabia pela venda do café ${ }^{18}$. De fato, em várias oportunidades Davatz estabelece essa comparação: “Será exagero [...] dizer-se que os colonos se acham sujeitos a uma nova espécie de escravidão, mais vantajosa para os patrões do que a verdadeira, pois recebem os europeus por preços bem mais moderados do que os dos africanos [...], sem falar no fato do trabalho dos brancos ser mais proveitoso que o dos negros? [...] E essa escravidão pode mesmo ser empreendida sob o amparo da lei." (Davatz 1980:161).

Sua descrição levantava questões extremamente perturbadoras para os fazendeiros, pois alertava sobretudo para as estruturas de dominação que retiravam do trabalhador livre qualquer possibilidade de defender seus interesses a partir dos instrumentos de justiça. Ao chegar à colônia, o imigrante recebia um regulamento que, em sua opinião, continha "leis perfeitamente razoáveis, mas cuja promulgação [...] compete às autoridades públicas, nunca a fazendeiros" (Davatz 1980: 95).

Dessa forma, a opressão se revestia de um sentimento de equiparação ao escravo, cuja condição era comparável à sua. No entanto, a estes restava a alternativa de comprar a liberdade, o que não acontecia com o colono, indefinidamente preso à fazenda por conta das dívidas assumidas desde o início da viagem. O sonho de obter uma propriedade produtiva e tornar-se independente parecia cada vez mais impossível. Além disso, a forma de tratamento assemelhava-se àquela dispensada aos escravos, o

\footnotetext{
${ }^{18}$ Uma análise apurada do grau de exploração presente na parceria está em Stolcke, Verena e Hall (1983: 80-122).
} 
que se explicava pelo fato de os proprietários estarem "habituados, desde a infância, a tratar com escravos e não terem aprendido até aqui a respeitar os direitos que assistem a um trabalhador livre. Aos olhos desses homens o colono só vale mais que os africanos pelo fato de proporcionar lucros maiores e de custar menos dinheiro. Em seu orgulho balofo eles encaram os colonos europeus com o desprezo que merecem os pretos escravos e por conseguinte acham inconcebível o fato de nós os colonos nos termos agitado e clamado por uma sindicância." (Davatz 1980: 233-234).

Aproximadamente um ano depois de sua chegada, Thomas Davatz conseguiu enviar ao cônsul no Rio de Janeiro, utilizando manobras para evitar o controle de sua correspondência, o relatório de que fora incumbido pelas autoridades suíças. Tornava-se pública, desta maneira, a realidade do sistema de parceria.

Foi nessas circunstâncias que se deu o levante dos colonos, objeto da terceira parte do livro. Evidentemente desapontados com a dura realidade da parceria, e profundamente descontentes com o pagamento referente ao primeiro ano trabalhado, os colonos decidiram reagir, buscando para tanto o apoio de Thomas Davatz. Este propôs que se elaborasse um projeto de colônia nos moldes daqueles já existentes no sul do país; em seguida, requisitariam ao governo imperial a doação de uma extensão de terra para implementar a nova colônia.

Além desse projeto, propuseram-se a enviar às autoridades provinciais o mesmo relatório já elaborado por Thomas Davatz, para servir de base para uma sindicância oficial - motivo que desencadeou o confronto direto com os fazendeiros.

Objetivamente, o "levante" consistiu num único entrevero entre os colonos e os donos da fazenda. Na manhã de 24 de dezembro de 1856, Thomas Davatz foi chamado à sede da fazenda para dar explicações a respeito de seu relatório sobre o sistema de parceria, que teria chegado à Suíça e provocado a vinda de um emissário para conferir as condições de vida e trabalho nas colônias da Companhia. Boatos de que Davatz seria preso ou castigado levaram um grupo de colonos a cercar a sede para garantir, se necessário, a integridade física de seu porta-voz.

Cabe notar que a discussão na sala da fazenda deu-se em duas línguas, uma vez que os principais interlocutores - Davatz e o próprio senador - só podiam comunicar- 
se através de um intérprete. Além do evidente conflito de interesses, chama a atenção a profunda divergência nos depoimentos sobre a rebelião, produzidos por Thomas Davatz e pelo senador Vergueiro, cuja versão foi anexada ao volume da Biblioteca Histórica por Sergio Buarque de Holanda.

Nessa, o velho senador faz alusão a um verdadeiro complô revolucionário orquestrado a partir de São Paulo por um cidadão suíço de nome Oswald, expulso da Suíça por se tratar de um líder comunista; Thomas Davatz seria um de seus agentes: "Os planos que se tem podido coligir dos ditos do mestre-escola e dos seus aderentes é (sic) estrondoso e impossível de levar a efeito, mas a tentativa pode produzir grandes males. Dizem que podem reunir todos os suíços, todos os colonos alemães e grande parte dos escravos cuja sorte é pior que a deles, e também alguns brasileiros descontentes, esperando pôr em armas 5.000 combatentes com que podem assenhorear-se desta Província e que depois republicanizarão o Brasil!",

O relato do senador foi enviado ao conselheiro Nabuco de Araújo, aventando a hipótese de uma "conspiração comunista" e alertando assim as autoridades imperiais; apresentado por José Vergueiro, filho do senador, o caso ganhava ainda maior dramaticidade: "[Davatz] apregoa aos seus que se acha de combinação com altas personagens que o Brasil vai ser invadido por forças européias, a exemplo do que os Estados Unidos tem feito, e que nessa Corte já se acham numerosos e avultados vasos de guerra, esperando apenas o momento, e brado dado pelos colonos desta província para desembarcarem e prestarem-lhe todo o auxílio" (Davatz 1980: 285-286).

$\mathrm{Na}$ visão das autoridades provinciais, o caso não se mostrava tão grave. O secretário de polícia, enviado a Limeira e adjacências para investigar as denúncias do senador, afirma em seu relatório que "sem deixar eu contudo de respeitar a convicção [do] Exmo. Senador Vergueiro, [...] não me convenci de haver transposto a agitação de Ibicaba os limites daquela colônia nem de serem outras as pretensões [...] senão

\footnotetext{
19 "Exposição do senador Vergueiro dirigida ao vice-presidente da Província sobre as ocorrências de Ibicaba", in Davatz (289) (Documentos inéditos).
} 
reformas e concessões concernentes às obrigações estipuladas e a outras matérias do regime econômico do estabelecimento" (Davatz 1980: 292-293).

Os “documentos inéditos" anexados por Sérgio Buarque de Holanda ao final do volume das Memórias permitem reflexões acerca do momento político vivido por São Paulo naquele tempo, apontando novos caminhos para uma pesquisa mais aprofundada. O temor de um descontrole da situação política, a alusão ao "comunismo" e ao regime republicano remetem à efervescência do momento vivido no continente europeu, cuja população encontrava na emigração uma possibilidade de solução para seus problemas.

$\mathrm{O}$ atrevimento dos colonos - na visão dos fazendeiros - não podia ficar sem punição; contudo, era inevitável que o caso tivesse desdobramentos, pois se por um lado a requisição de autoridades provinciais para garantir o controle da situação atendia à insegurança dos fazendeiros, por outro trazia consigo a intromissão do mundo exterior, do poder oficial, para dentro da fazenda.

Além do mais, o levante dos colonos provocou a vinda de agentes oficiais suíços cuja intenção consistia em confirmar a veracidade das informações de Thomas Davatz. Assim, existem dois relatórios oficiais (Heusser 1857 e Tschudi 1980) - trabalhados por Sérgio Buarque de Holanda em sua introdução - sendo um deles publicado em português também na Biblioteca Histórica. O primeiro, elaborado em fevereiro de 1857, pouco depois do levante, foi o do dr. Theodor Heusser, enviado com um ajudante pelos deputados suíços; o segundo, escrito em 1861, foi o de Jean-Jacques Tschudi, publicado pela primeira vez em 1865 .

O relatório Heusser é um documento precioso não apenas no que se refere às condições de trabalho nas colônias, que examina com cuidado, mas especialmente quanto às irregularidades cometidas pela casa Vergueiro. Além das formas corriqueiras de prejudicar os colonos - vendendo na fazenda produtos por preço mais alto do que no mercado local, ou utilizando recipientes de medida fora do padrão, sempre a favor da fazenda -, Heusser desvendava os mecanismos pelos quais a emigração aparecia como um bom negócio, que envolvia os interesses não apenas dos fazendeiros, mas ainda dos agentes e até mesmo das comunas suíças. No caso específico do levante de Ibicaba, a presença de Heusser garantiu o estabelecimento de um acordo pelo qual a fazenda 
se comprometia a cumprir os contratos e rever alguns de seus procedimentos, mas tudo com a condição de que o perigoso líder não mais permanecesse em suas terras.

De fato, Davatz ficou na fazenda até o início de março de 1857, quando deixou Ibicaba sozinho, diretamente para o Rio de Janeiro, onde esperou a chegada de sua família para retornar à Europa em junho do mesmo ano ${ }^{20}$.

Pouco depois do levante e em conjunção com o surgimento dos relatos de Theodor Heusser e Jean-Jacques Tschudi, desencadeia-se na Prússia uma intensa campanha contra a continuidade da emigração para o Brasil, que é oficialmente proibida em $1859^{21}$.

As inúmeras referências de Thomas Davatz à questão do "engodo" a que eram submetidos os candidatos à emigração apontam para uma nova direção de pesquisa: a questão da propaganda de emigração. Um levantamento inicial ${ }^{22}$, indica a produção significativa de obras, panfletos e jornais de língua alemã publicados especialmente nos centros de emigração, como Hamburgo por exemplo.

Além dessa documentação, duas outras memórias publicadas por ex-emigrantes foram analisadas com o objetivo de examinar a questão; é o aspecto da propaganda, mais diretamente referido à problemática do emigrante, que gostaríamos de aprofundar.

\footnotetext{
${ }^{20}$ Quanto à sua expulsão, há uma divergência de depoimentos; a família Vergueiro usa o termo expulsão, enquanto Davatz fala em acordo. Cabe notar, no entanto que sua saída da fazenda se dá de modo inesperado, e com a orientação expressa de ser secreta, evidentemente para evitar reações dos demais colonos. (Cf. Memórias...: 225).

${ }^{21}$ Sobre a posição do governo prussiano com relação ao tema, cf. Thomas Davatz, op. cit., p. 236 (n. 95). Parte do debate sobre o tema está resumido em volume de autoria desconhecida, Brasilianische Zustände und Aussichten im Jahre 1861. Mit Belegen nebst einem Vorschlag zur Aufhebung der Sklaverei und entfernung der Schwarzen aus Nord-Amerika. [Condições e panorama do Brasil no ano de 1861. Acompanhado de proposta para a abolição da escravidão e afastamento dos negros da América do Norte]. Berlin, Nikolaïsche Verlag, 1862.

${ }^{22}$ As bibliotecas consultadas foram a Biblioteca Sérgio Buarque de Holanda, na UNICAMP; Biblioteca Municipal de São Paulo Mário de Andrade; Biblioteca Hans Staden; Biblioteca do Instituto de Estudos Brasileiros da Universidade de São Paulo. Quanto aos textos alemães, a tradução é de minha autoria.
} 


\section{III}

O aumento do fluxo emigratório no início do século XIX dá origem a um tipo de literatura produzido especificamente para os candidatos à aventura. Os oficiais de recrutamento de mercenários, os agentes contratados para aliciar emigrantes e até mesmo os consulados brasileiros no estrangeiro desenvolvem mecanismos de propaganda baseados em relatos, cartas e panfletos.

Surgem na Alemanha informativos, folhas nas quais se publicavam os anúncios das empresas de colonização. Pode-se citar a Allgemeine Auswanderungszeitung, uma revista publicada em Rudolfstadt, centro de agenciamento de emigração; sobre essas publicações, Theodor Heusser afirma que em Rudolfstadt eram "aos montes e descaradamente impressos os panfletos elogiosos ao Brasil que não têm em vista os interesses dos colonos, que a todos aqueles agentes e escritores pagos só interessa mandar o maior número possível de cabeças para o Brasil, e para isso não poupam meio algum " (Heusser 1857:90).

Em 1853 inicia-se no Rio de Janeiro a publicação dos primeiros jornais de língua alemã $\tilde{2}^{23}$; pouco mais tarde, aparece no Rio de Janeiro o L'ami des colons, informativo destinado aos franceses daqui e de além-mar ${ }^{24}$.

A insistência de Thomas Davatz em convencer seu leitor sobre as desvantagens da emigração sugere uma questão importante: como e por que mecanismos os eventuais interessados na emigração obtinham as informações sobre a empreitada? Ele próprio sugere alguns, ao dizer-se iludido por "palestras, cartas e impressos" (Memórias: 161).

De fato, é possível encontrar, desde o início do século XIX, fontes de informação em língua alemã sobre as regiões de colonização; no início da vaga emigratória, podem ser encontrados verdadeiros guias, especificamente destinados aos interes-

\footnotetext{
${ }^{23}$ Der deutsche Einwanderer [O imigrante alemão] e Der deutsche Beobachter [O observador alemão]. Cf. Seyferth (2000: 17).

${ }^{24}$ A revista era publicada regularmente, a partir de fevereiro de 1857 no Courier du Brésil, hebdomadário publicado no Rio de Janeiro nos anos 1850.
} 
sados em emigrar; mais adiante, as cartas dos primeiros aventureiros, as memórias e depoimentos daqueles que voltavam frustrados da experiência, constituindo um conjunto de fontes que de certa maneira constrói um discurso sobre a emigração. É esse aspecto que pretendemos examinar mais detidamente.

\section{Impressos de propaganda}

Com as iniciativas oficiais para a colonização, surgiram na Alemanha os primeiros impressos informativos sobre o Brasil. Trata-se de uma literatura voltada para um público específico: o candidato à emigração. Uma dessas publicações, editada em 1826, de autoria de Christian Hahn, pretendia ser um guia para melhor conhecer o Brasil ${ }^{25}$. Para tanto, trazia dados específicos sobre as condições geográficas, informações sobre a história e possibilidades de atividades produtivas.

O texto chama a atenção primeiramente por enfocar as questões objetivas que se poderiam colocar aqueles que se interessassem pela idéia de emigrar; ao descrever as condições geográficas, o autor faz constantes aproximações e comparações com os países europeus: a região mineira é comparada com a Áustria, a imensidão das costas remete ao litoral prussiano, o Maranhão poderia "até mesmo ser tão pródigo na produção de alimentos quanto a Polônia, se fosse mais povoada" (Hahn 1826: 24). Em suma, Hahn analisava as potencialidades de enriquecimento nas diversas regiões do Brasil, destacando o papel estratégico que o país poderia ocupar no comércio mundial: "Em suma, o Brasil tem 950 milhas alemãs de costas, exatamente no centro da maior rota do comércio mundial, quase por toda parte com profundas desembocaduras de rios e baías seguras [...] Essa gigantesca superfície torna o Brasil incomparavelmente bem situado para o comércio internacional” (Hahn 1826:21).

\footnotetext{
${ }^{25}$ Hahn, Christian. Brasilien wie es ist. Eine Leitfaden für alle diejenigen, welche sich nähere Kentnisse über dieses Land erwerben wollen. Frankfurt am Main, Druck und Verlag von W.L.Wesché, 1826, 174 p. [Como é o Brasil. Um guia para todos aqueles que querem adquirir maiores informações sobre esse país].
} 
É possível perceber em algumas passagens uma certa comparação com a América do Norte, na qual as vantagens recaíam sobre o Brasil. Ao descrever as características geológicas do continente, por exemplo, o autor assinalava que desde o extremo norte as cadeias montanhosas ofereciam o risco de terremotos e erupções vulcânicas: “essas formações vulcânicas [...] se prolongam através do estreito do Panamá com maior força destrutiva ao longo de todo o norte da costa da América do sul".À medida que avançavam na direção meridional, atingindo as ilhas vulcânicas das Antilhas, modifica-se a morfologia geologica, encontrando-se então "altas montanhas, ricas em ouro, prata e outros metais. Aqui termina a característica vulcânica" (Hahn, 1826:23). Em outra passagem, o autor compara o litoral brasileiro com o norte-americano, ressaltando as possibilidades de navegação muito mais propícias no Brasil graças à abundância e à profundidade das baías e deltas fluviais.

Lamentando a impossibilidade de fornecer maiores detalhes, por conta da relativa novidade do território, Hahn assinalava que "a cada passo em direção ao interior, tropeça-se em interessantes descobertas em todos os reinos da natureza, e cada uma delas até então desconhecida" (Hahn, 1826:21).

Composto de dez capítulos, o livro examina as potencialidades da terra: comércio internacional, comércio de cabotagem, economia rural, bacias hidrográficas. Em seguida, faz um pequeno esboço da vida no Brasil, das doenças e pragas, e informa ainda sobre a vida do "rei e da rainha".

Anexo ao texto principal, e sem maiores explicações ou comentários, Hahn acrescentou a Constituição imperial. A preocupação em dotar seus leitores de informações sobre o estatuto legal do país parece indicar a importância atribuída à questão da explicitação dos direitos e deveres individuais e coletivos. Ao longo do texto, é possível perceber a pertinência dessa questão, na medida em que retrata as possibilidades de enriquecimento e prosperidade a partir do trabalho e do empenho individuais. Cabe ainda notar que o autor não faz referência alguma à questão da escravidão, restringindo-se a explorar as questões propriamente geográficas que poderiam interessar aos emigrantes.

O segundo aspecto a destacar na análise é a surpreendente conclusão do autor quanto à questão da emigração propriamente dita. Apesar da descrição profunda- 
mente otimista do país, e da verdadeira preocupação em explorar as possibilidades de enriquecimento, constituindo uma visão geral positiva sobre o Brasil, Hahn termina o texto advertindo os candidatos à emigração quanto aos riscos da empreitada. Aconselhando seus leitores a pesar cuidadosamente os prós e contras, concluía: "Ainda ninguém morreu de fome em terras alemãs, e cada regente cuida de seus súditos, mas vós quereis tudo mais espaçoso, quereis possuir terras em abundância, quereis dominar grandes porções de terra; vós não pensais que muitos quilômetros quadrados no Brasil não são utilizáveis, pois são ocupados por florestas impenetráveis, habitadas por animais selvagens, e que exigem esforços inumanos para se tornar utilizáveis" (Hahn1826: 122).

Contemporâneo ao texto de Christian Hahn, publica-se em Hamburgo em 1828 o texto de Friedrich von Weech com o mesmo propósito ${ }^{26}$. O objetivo de seu autor consistia claramente em oferecer a seus compatriotas um livro acessível e verdadeiro: "Clássicos trabalhos, com que homens eruditos e destacados brindaram a Europa não estão ao alcance de qualquer leitor"; além desses trabalhos, muito do que tinha sido escrito até então "é mais provável que leve [o leitor] a enganos do que propriamente o instrua"(Weech, 1828:3). Assim, Weech afirmava sua autoridade no assunto baseado na própria experiência, pois vivera no Brasil por algum tempo. Seu livro não pretendia ser uma distração aos leitores, mas consistia em fornecer informações úteis para quem tivesse a firme intenção de "tentar a sorte" por aqui.

Nesse sentido, o tom da obra se diferencia do primeiro guia; embora o conteúdo fosse semelhante ao de Hahn, as informações revelam uma vivência da situação, como por exemplo as indicações desde a chegada ao porto, apreciações sobre o aspecto da cidade (Rio de Janeiro), suas construções e seus arredores. O autor indicava ainda possibilidades de aprendizado da língua, costumes e religião dos moradores,

\footnotetext{
${ }^{26}$ Weech, Friedrich von. Brasiliens gegenwärtiger Zustand und Colonialsystem. Besonders im Bezug auf Landbau und Handel. Zunächst für Auswanderer. [A situação atual do Brasil e do sistema colonial. Especialmente com referência à agricultura e ao comércio. Especificamente para emigrantes]. Hamburg, bei Hoffmann und Campe, 1828.
} 
vida na Corte, etc. Os últimos capítulos são dedicados à atividade comercial e à agricultura propriamente ditas. Constituía-se na verdade como um guia para os recém-chegados de língua alemã.

Até então, o contingente de emigrantes alemães estava restrito às populações urbanas, especialmente artesãos e comerciantes (Seyferth 2000). Contudo, a propaganda de emigração começava a atingir maiores proporções tanto a partir das iniciativas oficiais de colonização quanto devido à iniciativa de recrutamento de mercenários para o exército brasileiro, já desde $1823^{27}$. É bastante citada na bibliografia a atuação de um agente de recrutamento para o Corpo de Estrangeiros do Exército Imperial, o major von Schäffer (Seyferth 2000). Figura controvertida, aparece ainda como um dos promotores da colonização de São Leopoldo, além de ser responsabilizado por criar uma imagem falsa e enganosa da terra com o objetivo único de enriquecimento. De fato, von Schäffer era agente oficial de recrutamento, recebendo por isso um pagamento anual da Coroa.

Um de seus detratores é Carl Seidler, ex-mercenário do exército imperial que passou dez anos no Brasil. Em suas palavras, o major von Schäffer "vendia o sangue de seus conterrâneos, à procura de um monte de ouro e de um canavial de açúcar, e que tão bem soube explorar para seus fins egoísticos a fúria aventureira da mocidade alemã. Foi Schäffer quem tosquiou tantas ovelhas inocentes para tecer um pelego quente para si próprio [...], o moderno vendedor de almas, que procurou introduzir na Alemanha, não sem êxito, em sentido oposto, o proibido tráfico de negros (Seidler 1980:28) $)^{28,}$.

O mesmo aspecto de exploração se verifica nas observações de Theodor Heusser, escritas quase quarenta anos depois: "[...] o que se deve dizer dos hamburgueses, como aqueles da casa Wille, que fizeram da colonização o rótulo para a mais pura especulação monetária? Mesmo que a casa Wille não receba nem uma comissão,

\footnotetext{
${ }^{27}$ Sobre o recrutamento ver a introdução de Aurélio Porto a Uma testemunha ocular. Contribuições para a História da Guerra entre o Brasil e Buenos Aires (1975: 5-14).

${ }^{28}$ Maiores detalhes sobre esse personagem estão em Seyferth 2000: 19-20).
} 
ou só 5 mil réis, como penso ter ouvido, continua sendo uma infâmia vender irmãos alemães para a escravidão brasileira" (Heusser 1857:91).

O livro de Seidler constitui outro depoimento significativo acerca da questão da emigração alemã. Após dez anos no Brasil, o autor retorna à Alemanha, onde escreve suas memórias. Ao contrário dos estudiosos, naturalistas e cientistas, Seidler se propõe a escrever sobre o Brasil em função do interesse que os europeus manifestavam sobre essa terra: "O Brasil sempre suscitou múltiplo (sic) interesse, primeiramente como terra privilegiada das fábulas européias das mil e uma noites, depois como império constitucional aportuguesado e, por fim, enxotado o seu Senhor, e como para não sair da fábula, qual corpo que se adorna de penas de pavão". Dentre os motivos mencionados para escrever seu relato, o autor aponta a intenção de aplacar "a louca sofreguidão emigratória de meus patrícios ainda não atenuada" ${ }^{29}$ ".

O relato de Seidler fornece algumas pistas sobre as formas de arregimentação de emigrantes, fazendo-nos refletir sobre as ilusões que moviam tantos aventureiros a procurar novas formas de vida. Assim como Thomas Davatz, Seidler também se confessa enfeitiçado pelas maravilhas contadas sobre o Brasil. E as semelhanças com esse autor não param por aí; trata-se antes de tudo de tentar alertar os aventureiros contra as falsas imagens propagadas pelos interessados diretos na emigração.

Conforme afirma Rubens Borba de Moraes, as memórias de Carl Seidler se encontram no rol daqueles escritos "mais com o intuito de atacar e desmoralizar que criticar imparcialmente o Brasil". Ressentido com o fato de não ter podido realizar seu sonho de enriquecimento, Seidler voltou à Alemanha e escreveu "um livro cheio de animosidade sobre o país que não o tornara milionário...”(Seidler 1980:11)"

Se é possível considerar as memórias de Seidler nesses termos, o inverso se dá com a leitura de Joseph Hörmeyer, mercenário alemão que esteve na década de 1850 no Exército imperial para lutar na guerra contra Rosas. De volta à Alemanha em

${ }^{29}$ Cf. Carl Seidler, Dez anos no Brasil (1980: 23). Note-se que o texto original foi publicado em 1835 , portanto um pouco posterior ao guia de Hahn. 
1854, escreve um livro sobre a colônia alemã no sul do Brasil ${ }^{30}$, além de colaborar em publicações sobre o tema da emigração.

Em 1863 Hörmeyer publicou em Leipzig uma brochura ${ }^{31}$ contando a história de um típico camponês de aldeia que deixara sua terra natal por falta de opção. De volta-apenas para visitar seu país - como bem sucedido emigrante proprietário de grandes extensões de terra no sul do Brasil, George relatava em sua aldeia as delícias da nova vida.

O livro tem um tom romanceado, cheio de diálogos, em que o personagem central descreve, durante as quatorze noites em que permaneceu em sua aldeia correspondendo a quatorze capítulos - sua experiência no Brasil. Segundo Sérgio Buarque de Holanda, "esse livro oferece ao longo de suas 250 páginas ricamente ilustradas todas as características de uma peça de propaganda de emigração". Contudo, não considera que Hörmeyer pretendesse responder "ostensivamente às críticas de Davatz" (Holanda 1976: 256).

Dadas as semelhanças entre George Höhrmeyer e Thomas Davatz, entretanto, penso ser possível perceber uma certa alusão ao episódio da colonização suíça em algumas passagens do texto. Afinal, George também vem como colono contratado por Vergueiro \& Companhia, passando pelas mesmas etapas de Davatz. O Capítulo 5 de Höhrmeyer é estruturado exatamente como o primeiro capítulo das Memórias de Davatz: a chegada, a viagem à fazenda, as impressões quanto à paisagem, o trabalho nas fazendas.

A comparação entre algumas passagens de ambos os textos permite pensar em George como um propagandista interessado em desmentir as afirmações do insatisfeito colono suíço. Thomas Davatz adverte sobre as surpresas da chegada a Santos e o descumprimento do contrato ainda no navio. "Outras novidades os colonos aprenderão mais tarde quando, após o desembarque, se virem trancados em um pátio enor-

\footnotetext{
${ }^{30}$ Südbrasilien. Ein Handbuch zur belehrung für Jederman, insbesondere für Auswanderer. Mit einer Karte. Von Kapitän J. Höhrmeyer. Hamburg, Carl Würger, 1857, XV+ 339 p. [Sul do Brasil. Um manual de informação para todos, especialmente para emigrantes. Com um mapa]

${ }^{31}$ Höhrmeyer [1863] (1966). Sobre as atividades de Hörmeyer nas publicações sobre emigração, cf. Abeillard Barreto, introdução.
} 
me, cercado de um lado pelo porto, de outro por muros e casas, com portas bem aferrolhadas e guardadas por sentinelas armadas" (Davatz 1980:88).

Joseph Höhrmeyer, ao contrário, descreve as maravilhas da recepção: “[...] ao amanhecer do dia seguinte chegou um procurador da casa Vergueiro, que nos mandou desembarcar e conduzir a um local determinado para o nosso alojamento, que era suficiente para nossas necessidades. Lá fomos amavel e atenciosamente recebidos. O povo na rua também nos saudava alegremente. E mal nos agasalhamos, recebemos frutas e flores como sinais de boas-vindas" (1863: 95-96).

A viagem entre Santos e Ibicaba é descrita por Davatz como um verdadeiro calvário: estradas precárias, o carro de boi, o sacrifício da caminhada, as dificuldades com a bagagem. George, embora aluda a algumas inconveniências, critica o excesso de carga trazido pelos viajantes: "Mas quanta coisa aquela gente tinha embalado! Cadeiras velhas, trapos e farrapos, trastes fora de uso, panelas de barro, em resumo, tudo o que não era fixo e pregado em suas antigas moradas!" (1863: 99).

Quanto à situação de permanente endividamento do colono, e mais especificamente quanto aos juros que deveria pagar, George os encara como uma justa compensação pelo negócio da emigração. Afinal de contas, constituía um risco para os proprietários a contratação de completos desconhecidos para o trabalho nas fazendas: "No dia seguinte fomos hospedados na fazenda e recebemos então nossa caderneta, na qual já estava registrada a nossa dívida [...] Recordo-me ainda que esta primeira parcela [...] importava em [...] mais de 500 florins renanos. E esta soma me emprestara um homem que eu nunca vira, do qual eu nunca ouvira falar! Ele a adiantara confiando em minha honradez, em meu futuro trabalho, a mim, a quem em minha própria pátria mesmo os meus melhores amigos e conhecidos não quiseram emprestar 80 florins"(1863:102).

Assim como este, numerosos exemplos de pontos de vista opostos podem ser encontrados numa comparação dos dois textos. Mas o que é fundamental é que George, ao contrário de Thomas Davatz, cumpre seu contrato pelos cinco anos estabelecidos; durante este tempo consegue economizar o suficiente para tornar-se independente e adquirir sua própria fazenda, que cresce continuamente em função de seu árduo trabalho. 
Visões divergentes sobre a mesma questão? Seria muito simplista reduzir a questão da emigração a um problema de propaganda; contudo, num universo de preocupações em que a sobrevivência individual, familiar ou de grupo se coloca, é possível compreender o papel significativo que, ao lado dos chamados "fatores de expulsão", desempenham os agentes aliciadores e a propaganda. Nesse sentido, o texto de Höhrmeyer não pode deixar de ser lido como uma "peça de propaganda", conforme alertou Sérgio Buarque de Holanda.

\title{
2. Cartas $^{32}$
}

\begin{abstract}
"Arrependo-me por quantos cabelos tenho na cabeça, do dia em que me decidi a emigrar, mas não posso confessá-lo. O sr. X. predisse o que me sucederia. Em vez de dar crédito a suas boas palavras, preferi confiar nas boas notícias que me chegavam, e o resultado é que não poderei, já agora, declarar-lhe que estava errado. Limito-me a dizer como vou passando [...] e silencio sobre o resto" (Davatz 1980:144).
\end{abstract}

O desabafo deste colono resume os diversos aspectos envolvidos na decisão de emigrar: ilusão, decepção e arrependimento. Mais que tudo, porém, ressalta a vergonha de confessar o próprio insucesso.

Ao contrário da propaganda, as cartas constituem um depoimento estritamente pessoal destinado a um público evidentemente diferente daquele a que se dirigiam os impressos. As cartas omitiam o fracasso ou inventavam o sucesso, o que era possível graças à improbabilidade de que tais informações fossem comprovadas por familiares ou conhecidos. Assim, mentir, enfeitar ou ocultar eram recursos frequientes de que os colonos lançavam mão ao enviar notícias à terra natal. Porém, dificilmente confessavam as frustrações da experiência.

\footnotetext{
${ }^{32}$ As cartas aqui mencionadas foram encontradas em Davatz, Heusser e Sommer, Friedrich. Die deutsche in São Paulo. São Paulo, 1945, 3 vols. (manuscrito).
} 
Além disso, não se pode esquecer o estrito controle exercido nas fazendas sobre a correspondência dos colonos, conforme informa o próprio Thomas Davatz; dessa forma, se porventura as cartas expressassem a realidade, dificilmente chegariam a seu destino. Por isso, via de regra chegavam à Europa as versões otimistas, as descrições favoráveis e atraentes. Para Davatz, esse otimismo enganador era responsável pela vinda dos incautos.

Um bom exemplo dessa visão positiva da experiência da emigração é uma carta enviada à Alemanha por um colono de Ibicaba em 1850 - portanto antes da vinda de Thomas Davatz. Note-se que as condições do contrato se transformaram ao longo dos anos, de modo que o relato aqui apontado pode ser fiel. De qualquer modo, o que nos interessa é apenas mostrar um exemplo das descrições que chegavam à Europa, e que poderiam motivar outros europeus a empreender a viagem.

Neste caso, o colono informava a seus familiares que, embora há sete meses no Brasil, ainda não tinha dinheiro; contudo, que não se preocupassem porque nada lhe faltava, uma vez que a fazenda lhe fornecia abrigo, e a produção de alimentos garantia-lhe a sobrevivência. Muito menos crítico que Davatz com relação ao sistema das cadernetas, esse colono via a figura do diretor da colônia fundamentalmente como a de um provedor de recursos.

Para provar seu bem estar, em comparação com a vida na Alemanha, o colono enumerava suas posses, uma plantação e uma pequena criação. "Eu mesmo tenho galinhas e nesse tempo que estou aqui comi mais frango do que em toda minha vida na Alemanha. Há mais de oito semanas não fazemos outra coisa senão nos ocupar em comer e dormir. Cada um trabalha quanto e como quer, e nessa terra ninguém tem motivos, como na Alemanha, para penar e trabalhar para se manter vivo. Quem se ocupar efetivamente das 6 às 10 da manhã e da 3 às 6 da tarde consegue tanto que é até possível guardar um tanto" (Sommer 1945, III; 1:107).

Como muitas das descrições de viajantes, o colono relatava a experiência de sua chegada, a sensação de estranhamento, as agruras do primeiro ano, as dificuldades de adaptação ao clima, as doenças tropicais, etc. Interessante notar que, embora fosse escrita por um colono de Ibicaba, a carta não detalhava muito bem o trabalho nos cafezais; apenas aconselhava seus compatriotas a não irem para as fazendas de 
café porque o trabalho era muito duro. Essa afirmação permite supor uma liberdade de escolha que de fato não se apresentava aos colonos, pois como se sabe o contrato era estrito quanto às finalidades do imigrante.

O próprio Thomas Davatz procurava explicações para o tom otimista contido em algumas cartas:

"O que contribuía particularmente para fechar os olhos de muitos à dura realidade era o crédito concedido em Ibicaba aos colonos, que não estavam habituados a essa prática na Europa. 'No Brasil tudo é melhor, - diziam. Os patrões brasileiros dão o necessário, mesmo quando não se tem com o que pagar. Aqui ninguém morre de fome'. O crescimento desproporcionado das dívidas, a condição de verdadeiros escravos em que viviam dissipavam-se " (Davatz 1940:143).

Visão semelhante apresentava o emissário suíço dr. Heusser, que depois de visitar as diversas colônias no Rio de Janeiro e em São Paulo mostrava-se surpreendido com o conteúdo da correspondência que chegava à Europa:

"Como é que só chegam a nós cartas favoráveis? Podemos encontrar para isso diversos motivos: maldade, burrice, exagero, falta de educação" (Heusser 1857: 83).

Heusser relatava ainda o fato de o administrador de Ibicaba ter posto Thomas Davatz sob vigilância policial para que não enviasse notícias negativas ao exterior; sua correspondência era sistematicamente aberta e as cartas que chegavam à Suíça só continham boas notícias. Este autor indica ainda uma outra fonte de enganos: alguns eram pagos para pintar o quadro róseo que constituía um incentivo para a emigração. Heusser cita o caso de um ex-colono, Jacob Murbach, cuja "fortuna, em todo o caso, não permite excluir [a hipótese] de que ele fez da escritura de cartas uma fonte de renda" (Heusser 1857: 83).

Essa opinião sobre as cartas está apoiada nas suas conclusões sobre o sistema de parceria; após ter visitado muitas colônias e estabelecido algumas explicações para o fracasso da experiência, conclui: "De fato, a possibilidade de um emigrante se sair bem na parceria não é muito maior do que ganhar o grande prêmio da loteria; mas não há 
pessoas suficientemente ingênuas para apostar na loteria?" (Heusser, 1857:93). De qualquer forma, o otimismo de alguns - mentiroso ou não - definia o destino de outros.

Foi na articulação entre as necessidades dos fazendeiros paulistas e as agruras das camadas pobres da população de algumas regiões da Europa que se desenharam as grandes linhas do episódio da colonização/emigração. As Memórias de Davatz nos dão a oportunidade de pensar os dois lados da questão. Sérgio Buarque de Holanda nos apontou os rumos mais produtivos, marcando a história da colonização de São Paulo, consagrando um tema. O que se sugere aqui é a inserção dessas memórias numa outra perspectiva: a motivação do autor, suas reflexões sobre seu tempo e seus problemas. Trata-se apenas de um esforço inicial de pesquisa, tanto de fontes quanto de uma pesquisa bibliografia européia, o que ainda está por ser feito.

As fontes até aqui trabalhadas indicam que a produção desses registros se dá num contexto de interesses bastante explícitos e complexos. Envolve opções individuais e coletivas, sobre as quais seus autores pretendiam exercer alguma influência. As palavras finais de Thomas Davatz não deixam dúvidas quanto a isso: "Creio agora ter feito tudo quanto esteve até aqui ao meu alcance para que se resolva assunto de tamanha gravidade. E se para o futuro ainda me for possível empreender alguma coisa de maior e mais eficiente, aqui estarei para acolher com viva alegria tal possibilidade [...] E assim salvaremos milhares de irmãos de uma terrível desgraça, ao mesmo tempo em que fecharemos a outros milhares o caminho da desolação (Memórias: 251)".

\section{Referências Bibliográficas}

ABRANTES, Marquês de. Relatório da repartição dos negócios estrangeiros apresentado à Assembléia Legislativa. Rio de Janeiro, Typographia Universal de Laemmert, 1863.

ANDRADE, Mario de. Táxi e Crônicas no Diário Nacional; estabelecimento de texto, introdução e notas de Telê Porto Ancona Lopez. São Paulo, Duas Cidades, Secretaria de Cultura, Ciência e Tecnologia, 1976.

ANDRADE, Mário de. “Agora é não desanimar!”. Diário Nacional, 9 e 16 de julho de 1931. 
AZEVEDO, Célia M. M. de. Onda negra; medo branco. O negro no imaginário das elites - Século XIX. Rio de Janeiro, Paz e Terra, 1987.

BELUZZO, Ana Maria. "A propósito d'O Brasil dos viajantes" in Revista USP n. 30. São Paulo, USP, junho/agosto de 1996.

BORGES, Vavy P. Tenentismo e Revolução brasileira. Sao Paulo, Brasiliense, 1992.

Brasilianische Zustände im Jahre 1861. Mit Belegen nebst einem Vorschlag zur Aufhebung der Sklaverei und Entfernung der Schwarzen aus Nord-Amerika. [Condições e panorama do Brasil no ano de 1861. Acompanhado de uma proposta para a abolição da escravidão e afastamento dos negros da América do Norte]. Berlin, Nicolaïsche Verlag, 1862.

Correspondência de Rubens Borba de Moraes a Sérgio Buarque de Holanda. 1940.

COSTA, Emília V. da. Da monarquia à República: momentos decisivos. São Paulo, Grijalbo, 1977, cap. V.

DAVATZ, Thomas. Memórias de um colono no Brasil (1850). Belo Horizonte: Ed. Itatiaia; São Paulo: Ed. da Universidade de São Paulo, 1980 (1 ${ }^{\mathrm{a}}$. ed., 1941).

DEAN, Warren. Rio Claro. Um sistema brasileiro de grande lavoura 1820-1920. Rio de Janeiro, Paz e Terra, 1977.

DEBRET, Jean-Baptiste. Viagem pitoresca e histórica ao Brasil. $3^{\mathrm{a}}$. ed. São Paulo, Martins, s/d.

DÓRIA, Renata P. “Uma viagem do olhar” in Martins, Carlos (org.) O Brasil redescoberto. Catálogo da exposição apresentada no Paço Imperial do Rio de Janeiro, setembro/ novembro de 1999.

FORJAZ, Djalma. O Senador Vergueiro - Sua vida e sua época (1778-1859): o homem social e o colonizador, o homem empreendedor, o homem político. São Paulo, Oficinas do Diário Oficial, 1924.

GOMES, Ângela de Castro (org.) História de imigrantes e de imigração no Rio de Janeiro. Rio de Janeiro, 7Letras, 2000.

HAHN, Christian. Brasilien wie es ist. Eine Leitfaden für alle diejenigen, welche sich nähere Kentnisse über dieses Land erwerben wollen. Frankfurt am Main, Druck und Verlag von W.L.Wesché, 1826, 174p. [O Brasil como ele é. Um guia para todos aqueles que querem obter maiores informações sobre esse país].

HEUSSER, Theodor. Die Schweizer auf den Kolonien in St. Paulo in Brasilien. Bericht des Herrn Heusser an die Direktion der Polizei des Kantones Zürich. Zürich, Druck und Verlag von Friedrich Schulthess, 1857. 
HÖHRMEYER, J. O que Jorge conta sobre o Brasil. Rio de Janeiro, Ed. Presença, 1966, (tradução de Bertholdo Klinger).

HOLANDA, Sérgio B. de "As colônias de parceria" in O Brasil monárquico. História Geral da Civilização Brasileira. Tomo II, vol.3. São Paulo, DIFEL, 1976, 3ª. ed., pp. 245-260.

KERST, G. Über brasilianische Zustände der Gegenwart. Berlin, 1853.

MORTON, G. Nash. "Fazenda de Ibicaba" in Revista do Instituto Histórico e Geográfico de São Paulo, vol. XXIII, 1925. São Paulo, 1927, pp. 256-278.

NICOULIN, Martin. A gênese de Nova Friburgo. Emigração e colonização suíça no Brasil 1817-1827. Rio de Janeiro, Fundação Biblioteca Nacional, 1995.

OBERACKER, Carlos H. “A colonização baseada no regime da pequena propriedade agrícola” in Holanda, Sérgio B. (org.) O Brasil monárquico. São Paulo, DIFEL, 1976, tomo II, vol.3. pp. 220-245.

PERRET-GENTIL, Carlos. A colônia Senador Vergueiro. Considerações de Carlos Perret-Gentil, Cônsul Geral da Suissa no Rio de Janeiro. Santos, Typ. Imparcial de F.M.R. d'Almeida, 1851.

SEIDLER Carl. Dez anos no Brasil. Belo Horizonte/São Paulo, Itatiaia/EDUSP, 1980.

SEYFERTH, Giralda, Imigração e cultura no Brasil. Brasília, Ed. UnB., 1990.

SEYFERTH, Giralda, "A imigração alemã no Rio de Janeiro" in Gomes, Angel de C. História de imigrantes e de imigração no Rio de Janeiro. Rio de Janeiro, 7Letras, 2000.

SOMMER, Friedrich. Die deutschen in São Paulo. Manuscrito. São Paulo, 1945, 3 volumes.

STOLCKE, Verena e Hall, Michael. "A introdução do trabalho livre nas fazendas de café de São Paulo" in Revista Brasileira de História n '. 6. São Paulo, Marco Zero, 1984, pp. 80-120.

SÜSSEKIND, Flora. O Brasil não é longe daqui. O narrador, a viagem. São Paulo, Companhia das Letras, 1990.

TAUNAY, Alfredo d'E. História do café no Brasil. Rio de Janeiro, Departamento Nacional do Café, 1939, tomo VI, vol. 8

TSCHUDI, J.J. Viagem às províncias do Rio de Janeiro e São Paulo. Belo Horizonte/São Paulo, Itatiaia/EDUSP, 1980.

Uma testemunha Ocular. Contribuições para a História da Guerra entre o Brasil e Buenos Aires. Belo Horizonte: Ed. Itatiaia; São Paulo, Ed. Da Universidade de São Paulo, 1975. introdução de Aurélio Porto. 
WEECH, Friedrich von. Brasiliens gegenwärtiger Zustand und Colonialsystem. Besonders in Bezug auf Landbau und Handel. Zunächst für Auswanderer. Hamburg, 1828, bei Hoffmann und Campe. [A situação atual do Brasil e seu sistema de colonização. Sobretudo com referência à agricultura . Especialmente para emigrantes].

WEIZINGER, Franz. Colônia Helvetia no Brasil. São Paulo, Escolas Profissionais Salesianas, 1935.

WITTER, José Sebastião. Um estabelecimento agrícola da província de São Paulo nos meados do século XIX. São Paulo, 1974. Separata da Revista de História. São Paulo, 1974. . A revolta dos parceiros. São Paulo, Brasiliense, 1986. 